\title{
Synthetic Studies Towards Arylpyrrole Derivatives via Heck- Matsuda Reaction
}

\author{
Cristiane S. Schwalm, ${ }^{1}$ Jailton Ferrari ${ }^{2}$ and Carlos R. D. Correia ${ }^{1 *}$ \\ ${ }^{1}$ Instituto de Química, UNICAMP, P.O. Box 6154, CEP 13083-970, Campinas, SP, Brazil \\ ${ }^{2}$ Departamento de Química - CCEN, UFPB, CEP 58051-970, João Pessoa, PB, Brazil \\ *roque@iqm.unicamp.br
}

Keywords: Keywords: arylpyrrole, Heck-Matsuda, pentabromopseudilin.

\section{INTRODUCTION}

The arylpyrrole unit is a widespread structural motif among biologically active compounds. For example, it is present on the structures of pyrrolnitrin (1), ${ }^{1}$ a potent antifungal agent, and pentabromopseudilin $(2),{ }^{2}$ which displays antibiotic, antitumor and lipoxygenase inhibitory activities (Figure 1).

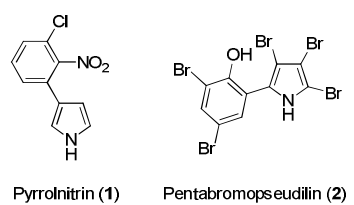

Figure 1. Biologically active arylpyrroles derivatives.

The Heck-Matsuda (HM) reaction employs arenediazonium salts as arylating agents and present several advantages over conventional protocols. It is a phosphine-free and air tolerant process. The more reactive nature of the arylating agent usually implies in shorter reaction times and milder reaction conditions. ${ }^{3}$ In this work we present the HM reaction as the key step in the synthesis of both 2 and 3-arylpyrroles, with applications in the synthesis of 2, isopentabromopseudilin 10 (its 3-aryl analogue) and 9 (a new 3-arylpyrrole derivative).

\section{RESULTS AND DISCUSSION}

The $N$-protected 3-pyrrolines $3 \mathbf{a}-\mathbf{b}$ were submitted to the HM reaction with the arenediazonium salt $\mathbf{4}$, leading to enecarbamates $5 \mathbf{a}-\mathbf{b}$ (Scheme 1).

Scheme 1. Synthesis of 3-arylpyrroles derivatives.

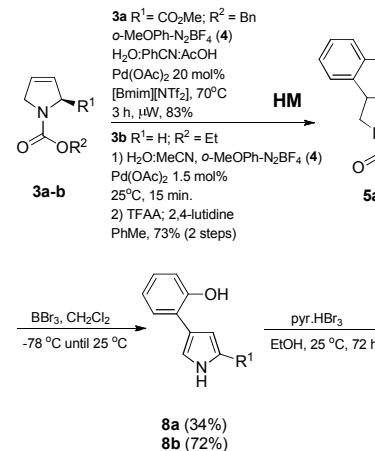

$$
\text { Sa-b }
$$
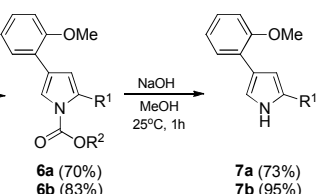
$6 \mathbf{b}(83 \%)$
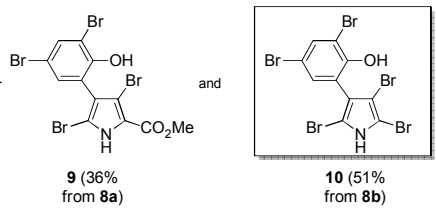

Aromatization of $\mathbf{5 a - b}$ employing DDQ afforded the 3-arylpyrroles $\mathbf{6} \mathbf{a}-\mathbf{b}$, which were deprotected under basic conditions and demethylated to afford $\mathbf{8 a - b}$. Finally, bromination of $\mathbf{8} \mathbf{a}-\mathbf{b}$ using pyridinium tribromide completed the total synthesis of isopentabromopseudilin (10, with $21 \%$ overall yield in 6 steps from $\mathbf{3 a}$ ) and its new analogue $\mathbf{9}$, with a substituent in the heteroaromatic cycle.

In a similar way, enecarbamate $\mathbf{1 1}$ was subjected to the $\mathrm{HM}$ reaction with 4 , leading to the Heck adduct 12 (Scheme 2).

Scheme 2. Synthesis of 2-arylpyrrole 14.

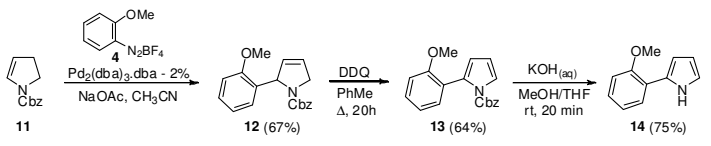

Aromatization of this compound furnished the 2arylpyrrole 13, which was deprotected under basic conditions to afford compound 14, in $32 \%$ overall yield in 3 steps from 11 (non-optimized results). Although these steps must be further optimized, this results represent a new formal total synthesis of pentabromopseudilin (2), since the conversion of 14 into $\mathbf{2}$ is already described in the literature. ${ }^{4}$

\section{CONCLUSION}

This work illustrates the viability of the HeckMatsuda reaction as a key step in the synthesis of arylpyrrole derivatives. The versatility of this approach was also demonstrated since both 2 and 3-arylpyrroles could be effectively prepared. Optimization of the synthetic route shown on Scheme 2, as well the development of a total synthesis of $\mathbf{2}$ are underway.

\section{ACKNOWLEDGEMENTS}

The authors thank CNPq for graduate fellowship (C.S.S.) and Fapesp for financial support.

\section{REFERENCES}

${ }^{1}$ van Pée, K. H.; Ligon, J. M. Nat. Prod. Rep. 2000, 17, 157.

${ }^{2}$ Toste, F. D. et al. Org. Lett. 2005, 7, 2501.

${ }^{3}$ Taylor, J. G.; Moro, A. V.; Correia, C. R. D. Eur. J. Org. Chem. 2011, 1403.

${ }^{4}$ Knölker, H-J. et al.; Angew. Chem. Int. Ed. 2009, 48, 8042.

$14^{\text {th }}$ Brazilian Meeting on Organic Synthesis $-14^{\text {th }}$ BMOS - September 01-05, 2011-Brasilia, Brazil 